\title{
A Corpus Tools-assisted Evaluation of Three ESP Textbooks in China
}

\author{
Chuying $\mathrm{Ou}^{1}$ \\ ${ }^{1}$ School of English Education, Guangdong University of Foreign Studies, Guangzhou, China \\ Correspondence: Chuying Ou, School of English Education, Guangdong University of Foreign Studies, 178, \\ Waihuan Donglu, Guangzhou Higher Education Mega Center, Guangzhou 510006, China.
}

Received: April 10, 2019 Accepted: May 17, 2019 Online Published: May 20, 2019

doi: 10.5539/elt.v12n6p URL: https://doi.org/10.5539/elt.v12n6p161

\begin{abstract}
ESP textbook plays an important role in facilitating students to develop their profession-related language skills. However, ESP textbooks published in China are less developed and often criticized as ignoring the training of language skills. This research aims to reveal the specific problems of China's ESP textbooks by conducting a multiple-case study. Three ESP textbooks used by ESP courses participants from G University in China were selected: "Computer Professional English Course" "Advertising English" and "Logistics English". The research investigated their performance focusing on six aspects: coverage of language skills, text features, coverage of discourse functions, recycling, organization and difficulty. The content was analyzed by three different corpus tools. It is found that the three textbooks place too much emphasis on reading and vocabulary, lacking the training of listening skill, speaking skill, as well as the delivery of certain learning strategies. All three textbooks involve a wide range of discourse functions. The texts are informative academic texts, but organized by subject matter only, rather than a synthesis of subject matter, language points and language skills. There is scarce recycling of language points in two of the books and texts through all of them do not indicate a rising difficulty. It is concluded that the drawbacks of the three ESP textbooks far outweigh their merits. By uncovering problems of three ESP textbooks in China the research provides useful reference for future ESP textbook compilation.
\end{abstract}

Keywords: corpus tools, textbook evaluation, ESP, China, multiple-case study

\section{Introduction}

Since a reform plan was launched in 2002 by Ministry of Education (MOE), College English teaching in China has experienced significant change during the past 15 years. Researchers and teachers put forward suggestions about how English should be taught in colleges. One of the most heated debates regards whether General English (GE) or English for Specific Purposes (ESP) should be the main course of College English teaching. Some scholars insist teaching GE (S. Wang \& Yao, 2013), while other scholars suggest replacing GE with ESP teaching (Cai, 2014; Cai \& Liao, 2010). There are also some researchers who advocate a co-existence of GE course and ESP course (Hu \& Xie, 2014; Wen, 2014). No matter what kind of opinions they hold, ESP teaching is more valued in today's college English teaching. In the seminal MOE document Guidelines on College English Teaching (draft), one of the highlights is that it involves ESP teaching and learning into the College English curriculum for the first time. Such change greatly embodies the positive effect of ESP teaching in cultivating international talents and enriching intention of the College English curriculum.

With the increasing significance of ESP teaching, studies have emerged which explored the curriculum planning, teacher development, assessment approach, materials design etc. as regard to ESP teaching and learning. Material design and evaluation have long been a concerning issue with the promoting of reform. They were criticized as unqualified, boring and inappropriate in difficulty. The most representative criticism is probably from Cai (2013), who pointed out most of the currently used ESP textbooks in China are "fake ESP textbooks" (p.3), because they do not accord with the real ESP teaching concepts. As the most important source of knowledge for students and teaching references for teachers, textbooks play a far-reaching role in ESP teaching reform. It becomes urgent to evaluate current ESP textbooks in order to examine their problems, thus providing suggestions for teachers and policy makers to select or adapt ESP textbooks.

This study therefore aims to find out the performance of ESP textbooks published in China and currently used by Chinese colleges. By adapting Hutchinson and Water's (1987) textbook evaluation method, three ESP textbooks were selected as the cases and analyzed with the assistance of corpus tools. They can help evaluators to make 
more accurate assessment. By figuring out the existing problems of ESP textbooks, the study may provide suggestions for publishers, colleges and teachers in selecting and adapting the textbooks, thus enabling them to further improve the quality of ESP courses.

\section{Literature Review}

The College English Syllabus released in 1999 promoted the position of ESP in China's College English teaching, as it stipulated for the first time that "Subject-related English" is one of the compulsory courses in college. Since then, ESP research in China has developed quickly and ESP textbooks studies have been given much more attention to. Scholarly work on ESP theory and practice (e.g. Guo, 2012; Huang, 2007; Mo, 2008; Yan, 2011) has all included textbook compilation and evaluation into research. Related studies can be summarized into three major themes, which reflect the issues that concern researchers most: (1) criteria for ESP textbook compilation and evaluation; (2) approaches for ESP textbook evaluation; and (3) problems of ESP textbooks and suggestions for their selection and adaptation.

Wang (2011) summarized nine principles for ESP textbook compilation, which were based on the review of some key textbook evaluation models. According to the nine principles, ESP textbooks should: (1) meet learners' needs; (2) be related to teaching objectives in syllabus; (3) select authentic communicative content and provide authentic communicative tasks and situation; (4) facilitate learner in using language to solve problems; (5) adapt itself to Chinese culture environment, learners and teachers; (6) provide systematic and comprehensive knowledge and reflect advanced achievements of the field; (7) have appropriate difficulty and staging; (8) utilize the Internet and multimedia; (9) cultivate learner autonomy and creativity. Though these principles were proposed initially for ESP textbook design, they also reflect the evaluation conception of the author, which may influence following researchers in devising evaluation model. However, some of these principles remain skeptical. For example, Cai (2013) criticized that it is not necessary for ESP textbooks to include comprehensive knowledge of the field, which would make the textbook a bilingual subject-based textbook, rather than a book for ESP teaching. Cai (2013) pointed out that ESP textbooks should present language features of specific professions so as to help students acquire language ability in their fields, instead of specific subject content.

Li's (2015) research tried to build up an evaluation model for China's ESP textbooks. The author argued that teaching content has the greatest importance when evaluating an ESP textbook, which involves language knowledge and skills, professional knowledge and teaching materials. Though justification for the importance of those indicators was presented, the article did not illustrate how the criteria could be used in practice, without a case to show how to evaluate a ESP textbook with the system. Therefore, it remains in the theoretical stage, rather than practical application. Still, Li's (2015) research is an important step of Chinese ESP textbook evaluation research, which promotes peoples' awareness of establishing evaluation model that fits China's tertiary English teaching situation. Similar to Li (2015), Sun (2014) established an evaluation model composed of two levels for ESP textbooks based on McDonough and Shaw's evaluation approach, applying AHP (Analytic Hierarchy Process) to determine the effects of different evaluation indicators. Despite of the simplicity of the evaluation approach, the assessment results of ESP textbooks provided by the author comprise only several scores, which could not really reflect the quality of the textbook. Other studies related to criteria for ESP textbook compilation and evaluation include Song, (2017) and Lou (2014). Both Song and Lou agreed that it is suitable to apply Hutchinson and Waters' (1987) evaluation model to assess performance of ESP textbooks.

A few articles tried to specifically investigate approaches of evaluating ESP textbooks. Wang and Wang (2017) pointed out that corpus tools could be applied to carry out evaluation of quantitative elements of ESP textbooks, which makes the evaluation process more objective. Corpus tools like WordSmith can be utilized to explore the vocabulary intensity, recurrence rate, coverage rate and etc. Such tools are significant, as they assist evaluators to implement quantitative analysis of ESP textbooks.

In terms of the problems of ESP textbooks in China, opinions from Mo (2003) and Gao (2009) are representative. Mo (2003) outlined three major problems regarding the situation of ESP textbooks development: (1) arbitrary choices of teaching materials due to the lack of guiding principles; (2) vacancy of guidance from ESP teaching theory; (3) inappropriate difficulty control. In order to promote ESP textbook design, he advocated that materials must be chosen on the basis of evaluation; materials should be developed under the guidance of linguistic theories and curriculum requirements; materials should have certain stages, fitting in the capabilities, aims and interests of learners; the theoretical study of ESP materials development should be strengthened. Gao (2009)'s remarks largely accord with Mo's, and he added one more problem that the genre of discourse and form of task in current ESP textbooks lack much diversification, which makes it difficult to achieve a deserved language learning affect and arouse learners' motivation. His suggestions for ESP textbook compilation is more specific, 
as he suggested that there should be a suitable combination of language and professional knowledge in the textbook; materials should be authentic in terms of texts, learning tasks and learning environment; textbooks should be diversified in both content and forms; textbooks should be inspiring, interesting and appropriate in difficulty. Other researchers (e.g. Ge, 2012; Liu \& Jia, 2014; Wei, 2013) hold similar views with them.

To summarize, three important themes connected with ESP textbook evaluation have emerged from the studies discussed so far: (1) model \& criteria, (2) approaches, and (3) problems \& suggestions, suggesting a wide attention upon related issues among researchers. Features of domestic ESP textbooks, especially shortages, have been investigated, reflecting concern about their quality. However, in terms of research method, most of the studies are based on qualitative analysis, with little quantitative investigation conducted to make the evaluation process more objective. Therefore, most of the evaluation results remain summaries of the researchers' experience which largely rely on their experience or impression, lacking in quantitative evidence to support the performance of the textbooks. In addition, such studies remain narrow in focus dealing mostly with textbook of business English (BE), leaving out ESP textbooks of other disciplines, such as engineering, management and law. This is probably because Business English is established as a major in many colleges in China, and BE textbooks are popular and widely used. Nevertheless, considering the amount of students learning ESP courses in Chinese colleges, there is critical need to improve ESP textbooks of disciplines other than BE. The insufficiency of previous studies indicates the necessity to conduct quantitative analysis in ESP textbook evaluation, as well as to expand the scope of ESP textbooks to be investigated.

Hutchinson and Water (1987) proposed that aims, content and methodology should be taken into consideration when evaluation ESP textbooks, which include skills, text features, recycling etc. Such elements are still the most important ones in ESP textbooks evaluation. Therefore, the research aims to answer this following question: What is the quality of the three ESP textbooks used in G university in terms of coverage of language skills, text features, coverage of discourse functions, recycling, organization and difficulty?

\section{Methodology}

This study employed the method of case study to investigate problems of ESP textbooks currently used in Chinese universities.

\subsection{Case Analysis}

Three ESP textbooks being used in G University were selected for the study. The following chart demonstrates some basic information of the three books:

Table 1. Information of the three ESP textbooks

\begin{tabular}{llll}
\hline & Publisher & Author & Publication date \\
\hline $\begin{array}{l}\text { Computer Professional } \\
\text { English Course }(C P E C)\end{array}$ & Science Press & Ke Xiaohua & 2017.07 \\
Advertising English $(A E)$ & Fudan University Press & $\begin{array}{l}\text { Zhang Zuxin, } \\
\text { Jiang Zhibin, Zhu Ye }\end{array}$ & 2012.03 \\
Logistics English $(L E)$ & China Machine Press & Wang Yacan & 2008.01 \\
\hline
\end{tabular}

All three textbooks are published by Chinese publishing houses and are written by Chinese scholars. They are respectively used by undergraduate students majoring in Computer, Advertising and Logistics in G University.

\subsection{Instruments}

Instruments applied for analysis include three kinds of corpus tools. They served as the most important tools in implementing evaluation of the textbooks, which include AntConc, AntWordProfiler and LanguageData. The content of the textbooks was made into electronic texts which could be analyzed by the corpus tools.

Among them, AntConc is a free corpus tools developed by Laurence Anthony, the Director of the Centre for English Language Education in Waseda University (Japan). Three basic functions of the tool were carried out which include concordance, wordlist and keyword list. Concordance indicates how target words are used in context. Wordlist on the other hand, counts all the words in the corpus and presents them in an ordered list which illustrate words that are most frequently used in a corpus. Keyword list presents words which are unusually 
frequent (or infrequent) in the corpus in comparison with the words in a reference corpus, identifying characteristic words in the corpus.

AntWordProfiler was employed to find out the coverage of a text by a certain word lists. It was used to figure out the frequency and distribution feature of the following word lists as regard to textbook content:

(1) Vocabulary lists of the textbooks

(2) Academic Word List (AWL)

The third corpus tool LanguageData is co-developed by Jin Tan from Sun Yat-sun University, Lu Xiaofei from University of Pennsylvania, Guo Kai from Shanghai Jiao Tong University and Li Baichuan from Youmi Technology, supported by the iTEST Project of Foreign Language Teaching and Research Press (FLTRP). It is an online intellective tool aimed at adapting English texts (https://languagedata.net/tester/). Based on a corpus of English examinations, it provides feedback of text difficulty in basically three dimensions: vocabulary, syntax and discourse. The results are indicated in the form of a number ranging from 2 to 8, which correspond to different levels of China's Standards of English Language Ability (CSE) released in June, 2018. This tool was used for analyzing the difficulty of each text in the three cases.

\section{Results}

For the purpose of analysis, all the texts in the three books were made into electronic texts. There are eight chapters in CPEC and most chapters include two texts, but some chapters include three texts. There are 16 units in $\mathrm{AE}$, with each unit containing two texts. Lastly, LE includes 11 topics in the book, but each topic has just one text.

\subsection{Coverage of Language Skills}

In order to see how different skills are reflected in the book, the content of the books was carefully examined. Such content refers to sections excluding the texts in the books. Only when the content (notes or exercises) has an explicit relationship with the skill will it be considered as the training of that skill. Table 2 summarizes the types of abilities reflected in the textbooks. The symbol "+" means that the book contains training or introduction of a certain skill, while "-" means the opposite.

Table 2. Skills training involved in three textbooks

\begin{tabular}{|c|c|c|c|c|}
\hline & & CPEC & $\mathrm{AE}$ & $\mathrm{LE}$ \\
\hline \multirow{3}{*}{ Listening } & $\begin{array}{l}\text { 1. Understand short academic lectures and professional } \\
\text { courses delivered in normal speed and relatively standard } \\
\text { pronunciation }\end{array}$ & - & - & - \\
\hline & $\begin{array}{l}\text { 2. Note down the main idea or key points and make short } \\
\text { summary }\end{array}$ & - & - & - \\
\hline & 3. Ask questions about unclear subject and main points & - & - & - \\
\hline \multirow{2}{*}{ Speaking } & $\begin{array}{l}\text { 4. Deliver brief subject-related statement and presentation } \\
\text { (about } 10 \text { minutes) }\end{array}$ & + & + & - \\
\hline & $\begin{array}{l}\text { 5. Apply appropriate conversation skills and strategies to } \\
\text { effectively participate in academic group discussion }\end{array}$ & - & - & - \\
\hline \multirow{3}{*}{ Reading } & $\begin{array}{l}\text { 6. Understand general academic articles of popular science \& } \\
\text { humanities and subject-related guided reading }\end{array}$ & + & + & + \\
\hline & $\begin{array}{l}\text { 7. Master critical reading skills (discriminate facts and } \\
\text { opinions; judge the reliability and credibility of information; } \\
\text { analyze, summarize and evaluate literature) }\end{array}$ & - & - & - \\
\hline & $\begin{array}{l}\text { 8. Master different discourse rhetorical means (definition, } \\
\text { classification, comparison, contrast, causality etc.) }\end{array}$ & - & - & - \\
\hline \multirow{2}{*}{ Writing } & $\begin{array}{l}\text { 9. Write post-reading summaries and literature review based } \\
\text { on multiple articles }\end{array}$ & + & - & - \\
\hline & $\begin{array}{l}\text { 10. Write paragraphs of definition, classification, illustration, } \\
\text { description, comparison, contrast, causality, explanation and }\end{array}$ & + & + & - \\
\hline
\end{tabular}


evaluation etc.

11. Write short academic articles supported by literature

12. Cite literature appropriately (summarizing main ideas, quoting directly, paraphrasing); know how to avoid plagiarism

\begin{tabular}{|c|c|c|c|c|}
\hline \multirow{2}{*}{ Vocabulary } & $\begin{array}{l}\text { 13. Master various strategies of vocabulary learning (guessing } \\
\text { meanings from root, affix and context etc.) }\end{array}$ & + & - & - \\
\hline & $\begin{array}{l}\text { 14. Master the most frequently used academic vocabularies in } \\
\text { professional field }\end{array}$ & + & + & + \\
\hline \multirow{4}{*}{$\begin{array}{l}\text { Learning } \\
\text { strategies }\end{array}$} & $\begin{array}{l}\text { 15. Study by making full use of resources provided by college } \\
\text { library and periodical database }\end{array}$ & - & - & - \\
\hline & $\begin{array}{l}\text { 16. Search information related to subject-learning with the } \\
\text { skill of searching literature }\end{array}$ & - & - & - \\
\hline & $\begin{array}{l}\text { 17. Analyze and summarize information from a variety of } \\
\text { channels }\end{array}$ & - & - & - \\
\hline & $\begin{array}{l}\text { 18. Study in groups with independent learning ability and } \\
\text { confidence of learning English }\end{array}$ & + & + & - \\
\hline
\end{tabular}

As we can see, many of the skills are not involved and trained in the three textbooks. All three textbooks place importance in reading and vocabulary. However, they lack the training of listening skill, speaking skill, as well as the delivery of certain learning strategies. LE is particularly in short of the practice of writing skill. Actually, what LE has emphasized most in the book is translating, as it has spared a lot of space for the practice of translating difficult Chinese sentences into English. Also, what CPEC has introduced most detailed is how to translate English for science and technology (EST), and how to write an abstract for an EST article.

\subsection{Text Features}

AntWordProfiler was applied to analyze features of the texts. The three tables display the coverage of AWL and GSL of the texts in these three textbooks, which is indicated by token\%. Token refers to the individual occurrence of a linguistic unit in speech or writing.

Table 3. The coverage of three word lists of CPEC

\begin{tabular}{lllllll}
\hline & Token & Token $\%$ & Type & Type $\%$ & Group & Group\% \\
\hline GSL 1st & 20738 & 69.56 & 1365 & 35.94 & 669 & 26.43 \\
GSL 2nd & 1822 & 6.11 & 432 & 11.37 & 253 & 10 \\
AWL & 3714 & 12.46 & 768 & 20.22 & 376 & 14.86 \\
\hline
\end{tabular}

Table 4. The coverage of three word lists of AE

\begin{tabular}{lllllll}
\hline & Token & Token $\%$ & Type & Type\% & Group & Group\% \\
\hline GSL 1st & 8495 & 71.37 & 1119 & 45.58 & 619 & 37.45 \\
GSL 2nd & 925 & 7.77 & 277 & 11.28 & 187 & 11.31 \\
AWL & 1474 & 12.38 & 526 & 21.43 & 314 & 19 \\
\hline
\end{tabular}

Table 5. The coverage of three word lists of LE

\begin{tabular}{lllllll}
\hline & Token & Token $\%$ & Type & Type\% & Group & Group\% \\
\hline GSL 1st & 33991 & 70.34 & 1687 & 37.25 & 762 & 26.92 \\
GSL 2nd & 3325 & 6.88 & 539 & 11.9 & 309 & 37.83 \\
AWL & 5998 & 12.41 & 992 & 21.90 & 449 & 15.86 \\
\hline
\end{tabular}


As can be seen in Table 3, Table 4 and Table 5, the coverage of AWL (Token\%) in CPEC, AE and LE are respectively $12.46 \%, 12.38 \%$ and $12.41 \%$. All of them are above $10 \%$, conforming to the feature of academic discourse (Coxhead, 2011).

Besides, in order to see whether the content of the text is related to the specific subject, another corpus tool (AntCon) was used to generate a keyword list by referring to British National Corpus (BNC). The top 50 key words lists are displayed below. "Keyness" tells us how distinctive a word is. Keywords that are not related to the subject were listed in explanation below.

Table 6. Key word list of CPEC

\begin{tabular}{|c|c|c|c|c|c|c|c|}
\hline Rank & Frequency & Keyness & Keyword & Rank & Frequency & Keyness & Keyword \\
\hline 1 & 106 & 1404.44 & internet & 26 & 41 & 250.85 & stored \\
\hline 2 & 220 & 1148.7 & Data & 27 & 45 & 242.26 & computers \\
\hline 3 & 98 & 846.88 & programming & 28 & 44 & 238 & database \\
\hline 4 & 154 & 775.33 & computer & 29 & 31 & 228.91 & node \\
\hline 5 & 119 & 689.35 & memory & 30 & 41 & 225.52 & storage \\
\hline 6 & 114 & 659.53 & network & 31 & 69 & 223.28 & figure \\
\hline 7 & 57 & 588.38 & pointer & 32 & 69 & 211.91 & type \\
\hline 8 & 59 & 544.63 & web & 33 & 44 & 209.33 & bus \\
\hline 9 & 50 & 437.23 & stack & 34 & 13 & 207.02 & $\mathrm{html}$ \\
\hline 10 & 91 & 431.14 & software & 35 & 13 & 207.02 & stackone \\
\hline 11 & 147 & 414.3 & system & 36 & 13 & 207.02 & stackpointer \\
\hline 12 & 51 & 394.93 & array & 37 & 110 & 204.39 & used \\
\hline 13 & 69 & 367.01 & code & 38 & 35 & 202.02 & devices \\
\hline 14 & 59 & 353.92 & languages & 39 & 33 & 199.95 & entries \\
\hline 15 & 66 & 343.92 & entry & 40 & 34 & 196.51 & hardware \\
\hline 16 & 94 & 332.64 & language & 41 & 55 & 188.26 & list \\
\hline 17 & 49 & 328.59 & networks & 42 & 28 & 185.95 & ports \\
\hline 18 & 65 & 319.25 & address & 43 & 81 & 185.51 & called \\
\hline 19 & 59 & 289.6 & operating & 44 & 63 & 185.51 & systems \\
\hline 20 & 54 & 289.16 & program & 45 & 49 & 184.38 & types \\
\hline 21 & 43 & 283.11 & programs & 46 & 21 & 176.39 & programmer \\
\hline 22 & 61 & 282.15 & user & 47 & 21 & 176.02 & $\mathrm{cpu}$ \\
\hline 23 & 58 & 280.65 & file & 48 & 549 & 168.56 & is \\
\hline 24 & 59 & 271.48 & users & 49 & 196 & 167.79 & can \\
\hline 25 & 51 & 265.16 & block & 50 & 19 & 165.7 & contiguous \\
\hline
\end{tabular}

Shown in Table 6, only 4 (used, called, is, can) out of 50 key words are not related to computing. Therefore, the texts in CPEC are capable of manifesting computing English to target learners.

Table 7. Key word list of AE

\begin{tabular}{llllllll}
\hline Rank & Fre. & Keyness & Keyword & Rank & Fre. & Keyness & Keyword \\
\hline 1 & 222 & 2222.42 & advertising & 26 & 35 & 96.73 & research \\
2 & 91 & 711.71 & marketing & 27 & 7 & 90.23 & copywriter \\
\hline
\end{tabular}




\begin{tabular}{llllllll}
\hline 3 & 67 & 420.97 & media & 28 & 16 & 89.99 & mix \\
4 & 65 & 367.81 & product & 29 & 13 & 89.57 & ethical \\
5 & 24 & 259.29 & advertisers & 30 & 17 & 89.22 & communications \\
6 & 43 & 257.99 & communication & 31 & 12 & 84.71 & advertisements \\
7 & 26 & 256.97 & ads & 32 & 16 & 84.5 & promotion \\
8 & 37 & 233.21 & consumer & 33 & 23 & 82.56 & relations \\
9 & 18 & 227.51 & behavior & 34 & 21 & 79.73 & television \\
10 & 19 & 223.52 & advertiser & 35 & 20 & 72.27 & sales \\
11 & 39 & 221.7 & message & 36 & 6 & 70.96 & globalization \\
12 & 29 & 206.78 & consumers & 37 & 21 & 70.94 & direct \\
13 & 31 & 198.1 & agencies & 38 & 17 & 68.67 & target \\
14 & 28 & 192.68 & creative & 39 & 6 & 65.11 & marketer \\
15 & 30 & 160.66 & strategy & 40 & 7 & 61.17 & commercials \\
16 & 30 & 160.02 & agency & 41 & 8 & 60.82 & promotional \\
17 & 34 & 153.51 & products & 42 & 6 & 60.6 & internet \\
18 & 22 & 148.92 & brand & 43 & 12 & 60.39 & strategies \\
19 & 7 & 118.3 & puffery & 44 & 7 & 59.56 & planner \\
20 & 23 & 115.89 & audience & 45 & 123 & 59.36 & Are \\
21 & 12 & 108.36 & marketplace & 46 & 15 & 58.84 & client \\
22 & 9 & 106.16 & marketers & 47 & 14 & 58.13 & selling \\
23 & 16 & 101.86 & messages & 48 & 13 & 57.78 & objectives \\
24 & 18 & 99.09 & ad & 49 & 17 & 57.74 & campaign \\
25 & 127 & 96.88 & or & 50 & 14 & 54.91 & patterns \\
\hline
\end{tabular}

Similar to CPEC, most of the key words in AE are related to advertising (are, or are not related), so AE also does a good job in delivering the subject-related content to learners.

Table 8. Key word list of LE

\begin{tabular}{llllllll}
\hline Rank & Frequency & Keyness & Keyword & Rank & Frequency & Keyness & Keyword \\
\hline 1 & 433 & 5773.04 & Logistics & 26 & 94 & 442.88 & customers \\
2 & 255 & 2840.18 & Inventory & 27 & 129 & 437.67 & companies \\
3 & 219 & 2407.59 & transportation & 28 & 92 & 428.44 & items \\
4 & 188 & 1830.07 & Warehouse & 29 & 41 & 426.91 & MRP \\
5 & 194 & 1329.65 & Customer & 30 & 57 & 422.43 & freight \\
6 & 131 & 1096.33 & Carrier & 31 & 35 & 382.46 & shipper \\
7 & 185 & 1090.16 & Materials & 32 & 94 & 355.37 & products \\
8 & 200 & 1082.47 & Supply & 33 & 482 & 327.35 & or \\
9 & 241 & 1027.12 & Cost & 34 & 65 & 323.07 & rail \\
10 & 194 & 1015.99 & Goods & 35 & 155 & 320.35 & system \\
11 & 98 & 1015.34 & Shipment & 36 & 50 & 320 & shipping \\
12 & 130 & 885.38 & Handling & 37 & 78 & 316.35 & firms \\
13 & 133 & 845.32 & Chain & 38 & 82 & 314.52 & equipment \\
\hline
\end{tabular}




\begin{tabular}{llllllll}
\hline 14 & 173 & 835.36 & Product & 39 & 62 & 314.03 & delivery \\
15 & 86 & 765.72 & Carriers & 40 & 72 & 312.35 & requirements \\
16 & 76 & 756.39 & Shipments & 41 & 74 & 312.29 & waste \\
17 & 78 & 646.63 & Packaging & 42 & 27 & 310.69 & inbound \\
18 & 200 & 642.48 & Service & 43 & 63 & 310.22 & location \\
19 & 156 & 636.18 & Costs & 44 & 25 & 300.8 & JIT \\
20 & 57 & 632.95 & warehousing & 45 & 137 & 290.39 & information \\
21 & 67 & 630.2 & Warehouses & 46 & 31 & 288.57 & labor \\
22 & 93 & 571.51 & Storage & 47 & 97 & 276.75 & systems \\
23 & 192 & 558.91 & Order & 48 & 40 & 273.39 & transit \\
24 & 148 & 482.53 & management & 49 & 41 & 265.01 & dock \\
25 & 118 & 462.77 & Firm & 50 & 132 & 263.06 & company \\
\hline
\end{tabular}

We can see from Table 8 that texts in LE also exhibit content highly related to logistics English, as 49 out of the 50 key words are connected to logistics ( $o r$ is not related).

To summarize, all the three textbooks contain academic texts which are closely related to the specific subjects.

\subsection{Coverage of Discourse Functions}

Discourse markers (DMs) serve as indicators of different discourse functions. Therefore, the texts were analyzed in order to see how DMs distribute through the book. The categorization of DMs is based on Wang and Zhu's (2005) research, and they based their classification on an earlier study conducted by Philip (1995). Shown in Table 9, there are 13 kinds of DMs in total, including 65 specific discourse markers.

Table 9. Categories of discourse markers

\begin{tabular}{ll}
\hline & Discourse markers \\
\hline 1. Additional DMs & Also, furthermore, moreover, besides, still, and, too, in addition \\
3. Conemplifying DMs & For instance, for example, such as \\
4. Repetitive DMs & But, on the contrary, however, on the other hand, nevertheless, yet \\
5. Causal DMs & In other words, namely, that is \\
6. Ordinal DMs & Since, because, so, thus, hence, therefore \\
7. Concluding DMs & Firstly, secondly, thirdly, next, in the first place \\
8. Concessive DMs & Though, although, even if, even though \\
9. Temporal DMs & After, meanwhile, now, before, when \\
10. Emphatic DMs & Above all, very, almost, actually, really, fully, extremely, completely, totally, \\
& indeed, incidentally \\
11. Conditional DMs & If, unless, whenever \\
12. Selective DMs & Either/or, other than, neither/nor, otherwise \\
13. Equivalent DMs & As well as, at the same time, or \\
\hline
\end{tabular}

With the help of AntConc, we can see how the distribution of these DMs through the book. Some of the DMs have different meanings in the texts, and their frequency of occurrence will only be counted when they indicate a kind of discourse function. For example, "so" will not be considered as a DM when it means "very" in the texts. Table 10, Table 11 and Table 12 respectively demonstrates how different DMs occur in the texts of CPEC, AE and LE. 
Table 10. Frequency of DMs of CPEC

\begin{tabular}{lll}
\hline & Frequency & Percentage \\
\hline 1. Additional DMs & 862 & $52.1 \%$ \\
2. Exemplifying DMs & 111 & $6.7 \%$ \\
3. Contrastive DMs & 75 & $4.5 \%$ \\
4. Repetitive DMs & 18 & $1.1 \%$ \\
5. Causal DMs & 77 & $4.7 \%$ \\
6. Ordinal DMs & 7 & $0.4 \%$ \\
7. Concluding DMs & 0 & $0.0 \%$ \\
8. Concessive DMs & 26 & $1.6 \%$ \\
9. Temporal DMs & 87 & $5.3 \%$ \\
10. Emphatic DMs & 47 & $2.8 \%$ \\
11. Conditional DMs & 57 & $3.4 \%$ \\
12. Selective DMs & 16 & $1.0 \%$ \\
13. Equivalent DMs & 271 & $16.4 \%$ \\
\hline
\end{tabular}

Table 11. Frequency of DMs of AE

\begin{tabular}{lll}
\hline & Frequency & Unit \\
\hline 1. Additional DMs & 419 & $57.6 \%$ \\
2. Exemplifying DMs & 31 & $4.3 \%$ \\
3. Contrastive DMs & 33 & $4.5 \%$ \\
4. Repetitive DMs & 4 & $0.5 \%$ \\
5. Causal DMs & 24 & $3.3 \%$ \\
6. Ordinal DMs & 4 & $0.5 \%$ \\
7. Concluding DMs & 0 & $0.0 \%$ \\
8. Concessive DMs & 7 & $1.0 \%$ \\
9. Temporal DMs & 34 & $4.7 \%$ \\
10. Emphatic DMs & 18 & $2.5 \%$ \\
11. Conditional DMs & 16 & $2.2 \%$ \\
12. Selective DMs & 5 & $0.7 \%$ \\
13. Equivalent DMs & 133 & $18.3 \%$ \\
\hline
\end{tabular}

Table 12. Frequency of DMs of LE

\begin{tabular}{lll}
\hline & Frequency & Topic \\
\hline 1. Additional DMs & 1637 & $54.6 \%$ \\
2. Exemplifying DMs & 167 & $5.6 \%$ \\
3. Contrastive DMs & 113 & $3.8 \%$ \\
4. Repetitive DMs & 32 & $1.1 \%$ \\
5. Causal DMs & 172 & $5.7 \%$ \\
6. Ordinal DMs & 6 & $0.2 \%$ \\
7. Concluding DMs & 0 & $0.0 \%$ \\
8. Concessive DMs & 23 & $0.8 \%$
\end{tabular}




$\begin{array}{lll}\text { 9. Temporal DMs } & 141 & 4.7 \% \\ \text { 10. Emphatic DMs } & 85 & 2.8 \% \\ \text { 11. Conditional DMs } & 75 & 2.5 \% \\ \text { 12. Selective DMs } & 22 & 0.7 \% \\ \text { 13. Equivalent DMs } & 523 & 17.5 \%\end{array}$

Shown in the tables, all three textbooks have displayed a wide variety of discourse functions, as almost each kind of DMs has accounted for a certain proportion in the texts. It was interesting that in all three books, there are no concluding DMs like "in summary", "to sum up", "in sum", and "in total". This suggests that there is a shortage of paragraphs which imply the function of concluding in the texts.

Nevertheless, it should be noted that apart from the DMs occurring in the texts, the textbooks do not include any extra introduction of any of the functions.

\subsection{Recycling}

In order to see how language points are recycled through the textbooks, the vocabulary lists in each book was extracted and made into family lists. A family is a group of words related to a headword that includes words with different parts of speech. For example, the family of "communicate" includes 10 related words: "communicated", "communicates", "communicating", "communication", "communications", "communicative", "communicatively", "communicator", "communicators", and "uncommunicative". Any word in the same family occurring in the texts will be considered as reoccurrence of that word family. The family lists were made with the help of an online word list producer "Compleat Lexical Tutor" (https://www.lextutor.ca/familizer/). The coverage of the family list was figured out by AntWordProfiler.

The vocabulary list in CPEC includes 168 words and they were made into a list containing 153 families and 9 words which were not able to be classified. Finally, 146 word groups turned out to have occurred in the texts. Table 13 to Table 15 respectively illustrates the amount and percentage of word families that occurred in different numbers of texts in three textbooks.

Table 13. The recycling of words in CPEC

\begin{tabular}{lll}
\hline Amount of texts occurrence & Amount of word families & Percentage \\
\hline 8 texts & 2 & $1.4 \%$ \\
7 texts & 6 & $4.1 \%$ \\
6 texts & 0 & $0.0 \%$ \\
5 texts & 7 & $4.8 \%$ \\
4 texts & 2 & $1.4 \%$ \\
3 texts & 10 & $6.8 \%$ \\
2 texts & 22 & $15.1 \%$ \\
1 texts & 97 & $66.4 \%$ \\
\hline
\end{tabular}

There are 21 texts altogether in CPEC, but the table shows that over $65 \%$ of word families occurred in just one text in the book. Approximately $15 \%$ of word families have reoccurred in another text. Overall, most of the words were not recycled in CPEC.

In terms of $\mathrm{AE}$, the vocabulary list contains 136 words, which was formed into a family list containing 125 groups and 9 words that were unclassified. 117 word groups finally occurred in the texts.

Table 14. The recycling of words in AE

\begin{tabular}{lll}
\hline Amount of texts occurrence & Amount of word families & Percentage \\
\hline 24 texts & 1 & $0.9 \%$ \\
\hline
\end{tabular}




\begin{tabular}{lll}
\hline 17 texts & 1 & $0.9 \%$ \\
16 texts & 1 & $0.9 \%$ \\
15 texts & 1 & $0.9 \%$ \\
12 texts & 1 & $0.9 \%$ \\
11 texts & 1 & $0.9 \%$ \\
9 texts & 2 & $1.7 \%$ \\
8 texts & 2 & $1.7 \%$ \\
7 texts & 3 & $2.6 \%$ \\
6 texts & 2 & $1.7 \%$ \\
5 texts & 2 & $1.7 \%$ \\
4 texts & 10 & $8.5 \%$ \\
3 texts & 7 & $6.0 \%$ \\
2 texts & 19 & $16.2 \%$ \\
1 text & 64 & $54.7 \%$ \\
\hline
\end{tabular}

Shown in Table 14, the recycling of words in AE is similar to CPEC, over $70 \%$ of the important words occurred in only one or two texts out of the 32 texts in the book. This means most of the words occurred only in a single unit of the textbook.

Regarding to LE, the word list contains 62 words and was made into a word list containing 43 word families and 7 words which were not classified. Finally, 46 word groups occurred in the texts.

Table 15. The recycling of words in LE

\begin{tabular}{lll}
\hline Amount of texts occurrence & Amount of word families & Percentage \\
\hline 12 texts & 9 & $19.6 \%$ \\
11 texts & 3 & $6.5 \%$ \\
10 texts & 6 & $13.0 \%$ \\
9 texts & 1 & $2.2 \%$ \\
8 texts & 4 & $8.7 \%$ \\
6 texts & 2 & $4.3 \%$ \\
5 texts & 2 & $4.3 \%$ \\
4 texts & 4 & $8.7 \%$ \\
3 texts & 7 & $15.2 \%$ \\
2 texts & 3 & $6.5 \%$ \\
1 texts & 5 & $10.9 \%$ \\
\hline
\end{tabular}

As we can see in Table 15, the recycling of words in LE is better than CPEC and AE. Though the LE just contains 42 word families, much less than that of the other two textbooks, almost $20 \%$ of them occurred in all 12 texts in the book. In total, almost $55 \%$ of them occurred in 6 texts or more and over $80 \%$ of the word families are recycled in at least two chapters.

\subsection{Organization}

The three textbooks are organized in different ways (CEPE in chapters, AE in units and LE in topics). In order to figure out how the content is organized through the book, the name of each Chapter/Unit/Topic is put together and shown in the following tables. 
Table 16. Topics in CPEC

\begin{tabular}{ll}
\hline Unit & Topic \\
\hline Chapter 1 & Information Technology and the Third Industrial Revolution \\
Chapter 2 & System Unit \\
Chapter 3 & Data Structures \\
Chapter 4 & Computer Programming and Its Languages \\
Chapter 5 & Operating Systems \\
Chapter 6 & Application Software-Database and Multimedia \\
Chapter 7 & Internet \\
Chapter 8 & Computer Network \\
\hline
\end{tabular}

Table 17. Units in $\mathrm{AE}$

\begin{tabular}{ll}
\hline Unit & Topic \\
\hline Unit 1 & The Dimensions of Advertising \\
Unit 2 & The Evolution of Advertising \\
Unit 3 & Advertising \& Marketing Process \\
Unit 4 & Marketing Communication Tools \\
Unit 5 & Integrated Marketing Communications \\
Unit 6 & Advertising Research \\
Unit 7 & Consumer Behavior \\
Unit 8 & Advertising Strategy \& Planning \\
Unit 9 & Creative Strategy \\
Unit 10 & Advertising Execution \\
Unit 11 & Advertising Media \\
Unit 12 & Public Relations \\
Unit 13 & Advertising Agency \\
Unit 14 & Advertising Ethics \\
Unit 15 & Advertising Regulation \\
Unit 16 & International Advertising \\
\hline
\end{tabular}

Table 18. Topics in LE

\begin{tabular}{ll}
\hline Unit & Topic \\
\hline Topic 1 & Introduction to Logistics Management \\
Topic 2 & Order Management and Customer's Service \\
Topic 3 & Packaging and Material Handling \\
Topic 4 & Transportation Management \\
Topic 5 & Inventory Management \\
Topic 6 & Warehousing Management \\
Topic 7 & Logistics Facility Location Management \\
Topic 8 & Logistics Information Management \\
Topic 9 & Reverse Logistics \\
Topic 10 & Global Logistics \\
\hline
\end{tabular}




Topic $11 \quad$ Introduction to Supply Chain Management

Topic 12 Career in Logistics

From the tables above we can see that in all the three textbooks, content is organized by subject-matter, instead of language points or language skills. Each Chapter/Unit/Topic deals with one theme related to the subject itself and there is no particular introduction of language knowledge and skill in each unit. The following charts present how the content is organized within a Chapter/Unit/Topic.

Table 19. Chapter organization of CPEC

\begin{tabular}{ll}
\hline Components & Content involved \\
\hline Introduction & Brief summary and Lead-in of the chapter \\
Section A & Reading material, word list, notes, exercises \\
Section B & Reading material, word list, notes, exercises \\
Section C & $\begin{array}{l}\text { Review, supplementary reading material, language knowledge, exercise, evaluation form } \\
\text { of learning outcomes }\end{array}$ \\
\hline
\end{tabular}

Obviously, in CPEC, the content is organized by a set of pattern of components within the unit. It follows an order of introduction - specific knowledge-review, which seems to be clear and reasonable. Components in both Section A and Section B are quite patterned, including a text, word list along with text, notes and exercises. However, components in Section $\mathrm{C}$ are not consistent through the units.

Table 20. Components of Section C in CPEC

\begin{tabular}{|c|c|c|c|c|}
\hline Chapter & Components and the & $r$ order & & \\
\hline Chapter 1 & $\begin{array}{l}\text { reviewing } \\
\text { questions }\end{array}$ & $\begin{array}{l}\text { supplementary } \\
\text { reading }\end{array}$ & $\begin{array}{l}\text { grammatical } \\
\text { knowledge }\end{array}$ & exercises \\
\hline Chapter 2 & $\begin{array}{l}\text { reviewing } \\
\text { questions }\end{array}$ & Translation & & \\
\hline Chapter 3 & $\begin{array}{l}\text { reviewing } \\
\text { questions }\end{array}$ & $\begin{array}{l}\text { grammatical } \\
\text { knowledge }\end{array}$ & evaluation form (1) & \\
\hline Chapter 4 & evaluation form (1) & reviewing questions & & \\
\hline Chapter 5 & $\begin{array}{l}\text { supplementary } \\
\text { reading }\end{array}$ & Exercises & evaluation form (2) & \\
\hline Chapter 6 & $\begin{array}{l}\text { reviewing } \\
\text { questions }\end{array}$ & $\begin{array}{l}\text { supplementary } \\
\text { reading }\end{array}$ & $\begin{array}{l}\text { grammatical } \\
\text { knowledge }\end{array}$ & \\
\hline Chapter 7 & $\begin{array}{l}\text { supplementary } \\
\text { reading }\end{array}$ & $\begin{array}{l}\text { grammatical } \\
\text { knowledge }\end{array}$ & evaluation form (3) & \\
\hline Chapter 8 & $\begin{array}{l}\text { reviewing } \\
\text { questions }\end{array}$ & $\begin{array}{l}\text { grammatical } \\
\text { knowledge }\end{array}$ & & \\
\hline
\end{tabular}

Table 20 illustrates the content of Section C in CPEC. Clearly, there are not any two sections which share the same constitution of components and the components do not follow the same order as well. For example, almost all chapters involve a set of reviewing questions at the beginning of the section, except Chapter 4 (putting them after an evaluation form), Chapter 5 and Chapter 7 (excluding the questions). In addition, supplementary readings only occur in four chapters: Chapter 1, Chapter 5, Chapter 6 and Chapter 7, which do not indicate any regular pattern. The same feature is found in grammatical knowledge, exercises and evaluation form. To summarize, the organization of Section $\mathrm{C}$ through the book is unsystematic. The following tables demonstrate the unit organization of AE and LE. 
Table 21. Unit organization of AE

\begin{tabular}{ll}
\hline Components & Content involved \\
\hline Part one Discussion & True or false questions, multiple choices, topic for discussion \\
Part two Text & Text, vocabulary and notes, exercises \\
Part three Follow-up & Additional reading, exercises, activities \\
Part four Term-expansion & Vocabulary list (English-Chinese) \\
\hline
\end{tabular}

Table 22. Topic organization of LE

\begin{tabular}{ll}
\hline Components & Content involved \\
\hline Case study & A classic case related to the topic \\
Overview & An brief introduction of the chapter \\
Text & A long text with several sub-sections \\
Vocabulary & Vocabulary list with Chinese meaning \\
Difficult sentences & English sentences with their Chinese translation \\
Core words and expressions & Chinese explanation of the words and related expressions \\
Exercises & Answering questions, translation (English to Chinese), translation \\
& (Chinese to English) \\
\hline
\end{tabular}

As it is shown above, both $\mathrm{AE}$ and LE organize their content within a unit by a set of pattern of components, the same as CPEC. AE follows a unit structure of discussion, text, exercises and vocabulary, and LE organizes the content mainly in the order of case study, text, vocabulary, difficult words and sentences, and exercises. To summarize, the content is organized by subject matter across the chapters/units/topics, without syllabus of either language points or language skills. When within the chapter/unit/topic, the sequencing of all three textbooks follow the order of lead-in, text, vocabulary and exercises, without component about language skills.

\subsection{Difficulty}

In order to figure out the difficulty of the texts, the text analysis tool "LanguageData" was applied. As it is mentioned in the introduction of instruments, it can be used to analyze the difficulty of vocabulary, syntax and the overall difficulty of the text. The following picture is a sample of the report of a single text analyzed, above which is an explanation of the sample.

In Figure 1, the number ranging from 2 to 3,3 to 4,4 to 5, 5 to 6,6 to 7,7 to 8 respectively corresponds to level 2 (primary school), level 3 (junior high), level 4 (senior high), level 5 (college), level 6 (college), and level 7 (college) in CSE. The small chart in the figure illustrates the difficulty of vocabulary (7.50), syntax (3.79) and the whole text (6.49). 


\section{英语阅读分级指难针}

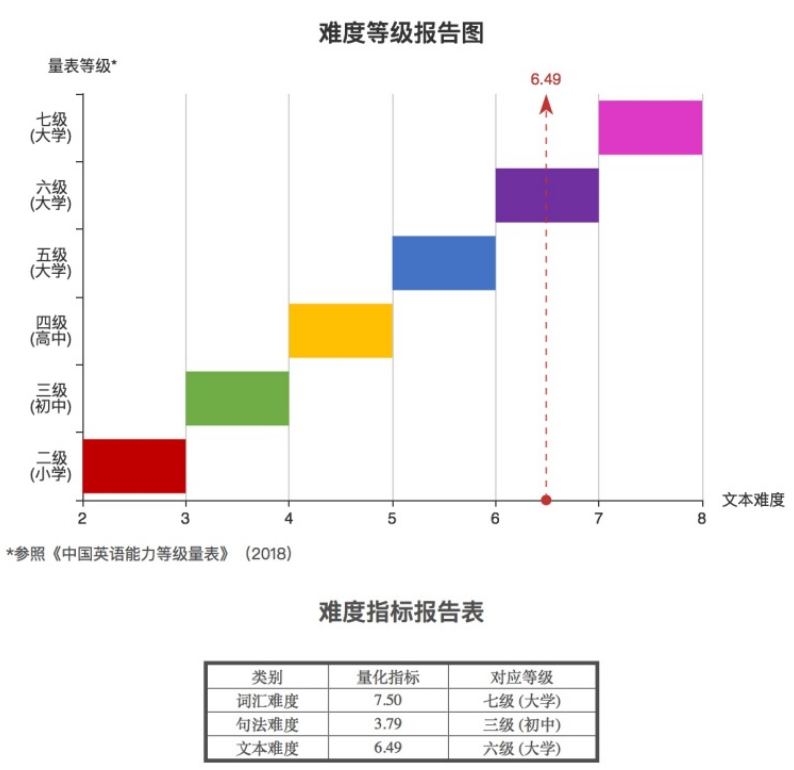

Figure 1. Sample of difficulty report

Some of the texts (one in CPEC and seven in LE) are too long for analysis, so they had to be split into several parts. The final result is the average of different parts. Figure 2 to Figure 4 present the difficulty of the three cases, where "T" stands for "Text", "C" represents "Chapter", "U" stands for "Unit" and "To" stands for "Topic".

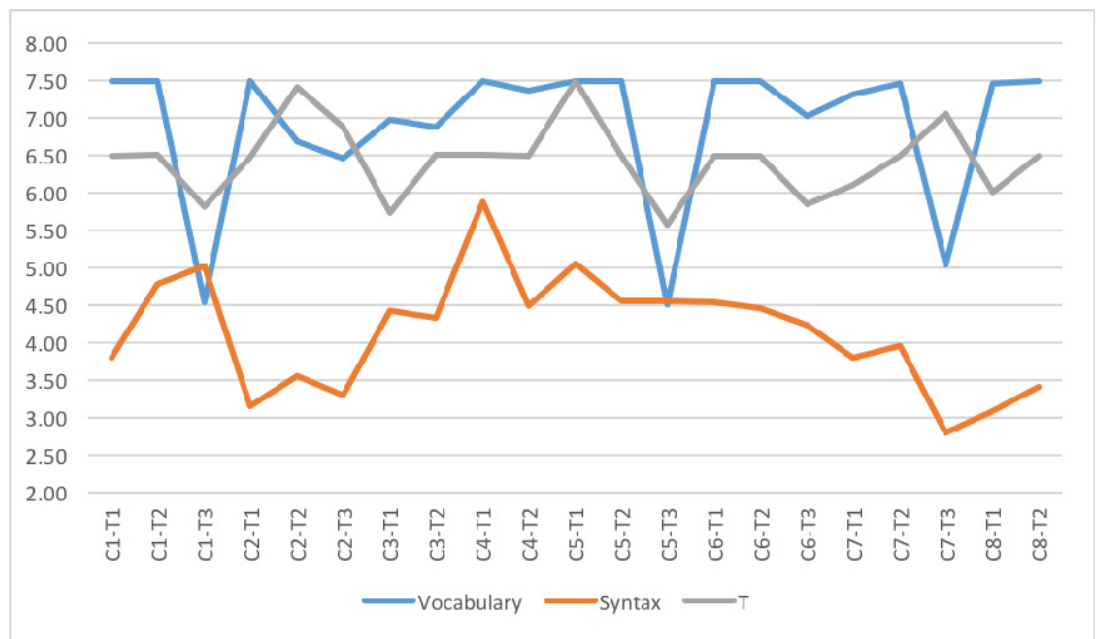

Figure 2. Difficulty of CEPC

As can be seen in Figure 2, the difficulty of vocabulary, syntax and whole text all fluctuate through the book. The difficulty of syntax is rather low, as most the texts fall into the syntax level of junior or senior high (between 3 to 5). Nevertheless, the sentences structure of Text 3 in Chapter 7 is extremely easy (2.8) that it falls into the level of primary school, and the syntax of Text 1 in Chapter 4 is unusually difficult (5.88) that it belongs to the level of college. Vocabulary and whole text are at the college level (above 5), but the difficulty of vocabulary fluctuates more greatly than that of whole text. Shown in the figure, difficulty of vocabulary of Text 3 in each 
chapter is all lower than that of Text 1 and Text 2 in the same chapter. However, vocabularies in Text 3 in Chapter 1,5 and 7 are particularly easy, the difficulty of which being respectively $4.50,4.55$ and 5.04 . The difficulty of whole text follows a similar trend as vocabulary, except that in Chapter 7, the difficulty of Text 3 (7.05) is higher than Text $1(6.10)$ and Text 2 (6.49). To summarize, although the difficulty of all three aspects fluctuate through the chapters, the difficulty of whole text fluctuates to a less extent.

Figure 3 demonstrates the difficulty of AE. There are 16 units and 32 texts in AE so the line graph looks denser.

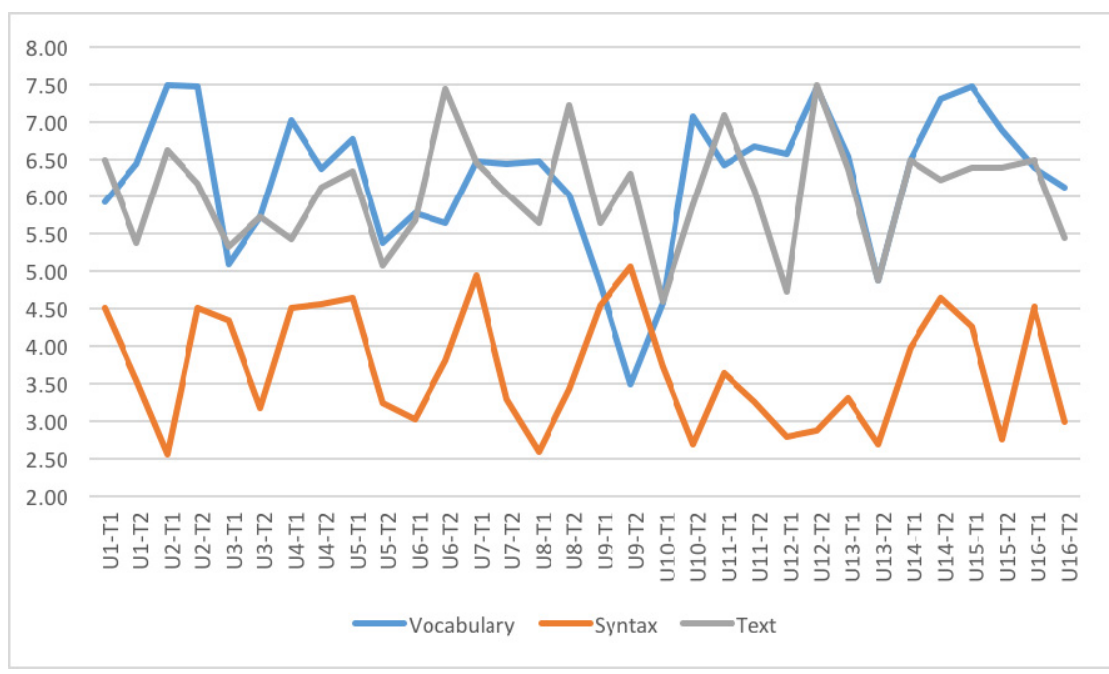

Figure 3. Difficulty of AE

Resembling CPEC, we can see in Figure 3 that the difficulty of vocabulary, syntax and whole text fluctuate through the book. The difficulty of syntax is generally lower, fluctuating between 2.5 to slightly over 5 . Seven out of the 32 texts in the book have unusually easy sentences (below 3), with the rest of them almost falling into the level of junior and senior high. The difficulty of vocabulary and whole text all fluctuate greatly and seem not to follow any patterns. The difficulty of vocabulary fluctuates between slightly below 3.5 to 7.5 , ranging from Level 3 (junior high) to Level 7 (college). Vocabulary of Text 2 in Unit 9 is easiest, the difficulty score of which being 3.49. The difficulty of whole text fluctuates between 4.5 to 7.5 , with 3 out of the 32 texts being too easy and falling into Level 4 (senior high).

The following Figure 4 demonstrates the difficulty of vocabulary, syntax and whole text of LE. Different from CPEC and AE, the difficulty of vocabulary and whole text of LE remain rather stable through the book. In terms of vocabulary, the difficulty score levels out at about 7.5 (Level 7 of college). Regarding to whole text, the difficulty remains steady at approximately 6.5 , in spite of a fall to 5.5 in the text of Topic 12 . Again, the difficulty of syntax is smaller than vocabulary and whole text, fluctuating between 3 to 5 , all of which fall in Level 3 (junior high) and Level 4 (senior high) of CSE. 


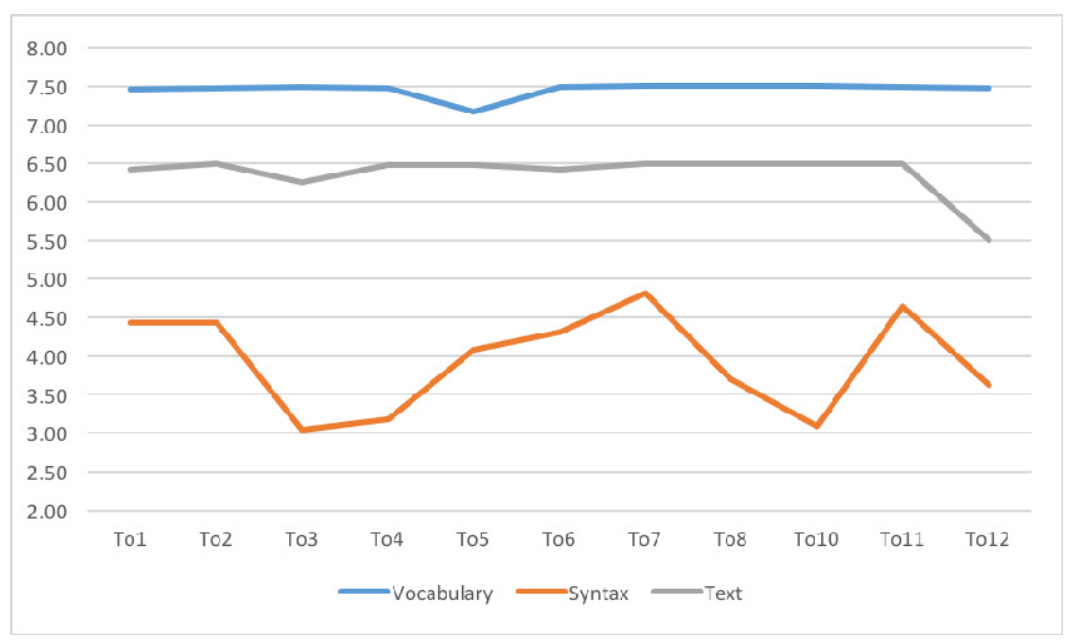

Figure 4. Difficulty of LE

To summarize, in all three textbooks, the syntax is comparatively easy, the difficulty of which belongs to Level 3 (junior high) and Level 4 (senior high). This accords with their text features as the texts are informative with a lot of discussion rather than entertaining with beautiful language. The difficulty of vocabulary and whole text fall into college level, ranging from Level 5 to Level 7. However, the difficulty of vocabulary and whole text of LE remain much more stable than that of $\mathrm{CPEC}$ and $\mathrm{AE}$, whose difficulty fluctuates through the book without following any patterns. Both CPEC and AE have texts unusually easier than other texts in the books.

\section{Discussion}

As can be seen from the results, the drawbacks of the three textbooks mainly lie in the imbalanced training of language skills, the inappropriate recycling, organization, difficulty of the content. The results have empirically confirmed many of the problems pointed out by previous researchers (e.g. Ge, 2012; Liu \& Jia, 2014; Wei, 2013). One of the notable criticisms is that ESP textbooks compiled by Chinese scholars have overemphasized the systematization and comprehensiveness of content, and ignored the training of various academic ability (Cai, 2013). Among the three cases examined in the study, only CPEC has explicitly demonstrated academic knowledge and skills, such as writing an abstract. Nevertheless, the account of explanation and training of academic skill in all three books are still far from enough.

Another problem revealed by the research accords with what is indicated by Mo (2003) that there is an "inappropriate difficulty control" in the ESP textbooks. Seen from the results, texts in none of the textbooks have gradually become more and more difficult. Some texts are particularly easier or more difficult than the other texts. Mo (2003) pointed out that this is one of the prominent drawbacks of China's ESP textbooks and it is necessary that materials are designed with stages and cater to the growth of students' capabilities and interest. Similarly, Gao (2009) argued that the genre of discourse and form of task of the ESP textbooks are monotonous rather than diversified, which may weaken the learning effect and distract students' attention.

Beside the problems previously pointed out by the researchers, the study also proves that the textbooks do not have a good recycling of language points. With a low frequency of recycling, students may not have opportunities to consolidate the topics and language knowledge they have encountered. Cunningsworth (1995) has emphasized the importance of recycling as learners need to meet items on different occasions in order to remember them, gain fluency in using them and finally achieve a full understanding of their meanings. Unlike grammar which is very likely to turn up again, it is very possible that vocabulary items appear once or twice and then disappear forever if the textbook writers do not pay particularly high attention to recycle them.

\section{Conclusion and Suggestions}

This study conducted a multiple-case study to evaluate the quality of three selected ESP textbooks used in G university in China. These three textbooks are Computer Professional English Course (CPEC), Advertising English (AE) and Logistics English (LE). The findings indicate that the three textbooks have more drawbacks than merits in many aspects: coverage of language skills, text features, coverage of discourse functions, recycling, organization and difficulty. To be specific, the three textbooks place much significance in reading and vocabulary, lacking the training of listening skill, speaking skill, as well as the delivery of certain learning 
strategies. However, they display a wide variety of discourse functions. The texts in the books are informative academic texts, organized by subject matter only, rather than a synthesis of subject matter, language points and language skills. There is scarce recycling of language points in CPEC and AE, and texts through all three books do not indicate a rising difficulty.

According to the drawbacks revealed by the results, future compilation and adaptation of ESP textbooks may need to pay attention to the following issues. First of all, the books might need to achieve a better balance between the training of different language skills. Listening, speaking and related learning strategies should account for a great proportion in the content, as they are possibly what students perceived as necessary, insufficient and desirable. It is also suggested that different sub-skills of listening, speaking, reading, writing, vocabulary and learning strategies be clearly stated and integrated into the exercises and activities. Secondly, ESP textbooks may need to improve the content regarding to text features, recycling, organization and difficulty. The layout of the textbooks should be optimized by adding some illustrations in order to attract students' interests. It is also recommended that language knowledge and training of skills are recycled through the book so that students can consolidate what they have newly learnt. The organization of the content could follow a syllabus which combines language points, language skills and subject matter, and the difficulty of texts should increase gradually as the content advances.

\section{Acknowledgements}

This work was supported by the Graduate Research and Innovation Project of Guangdong University of Foreign Studies, Guangzhou, China [grant number 18GWCXXM-38; name of project: DSOM model-based ESP textbook evaluation--a multiple case study in G university]. I would also like to express my sincere gratitude to Dr. Chen Jinshi who gave valuable comments on the earlier drafts of this paper.

\section{References}

Cai, J. (2013). Zhuanye yingyu jiqi jiaocai dui woguo gaoxiao ESP jiaoxue de yingxiang (The influence of Subject-based English and its textbooks on ESP teaching in colleges of China). Waiyu Yu Waiyu Jiaoxue (Foreign Languages and Their Teaching), 2, 1-4. https://doi.org/10.13458/j.cnki.flatt.003891

Cai, J. (2014). Cong tongyong yingyu dao xueshu yingyu— - huigui daxue yingyu jiaoxue benwei (From GE to EAP: A return to the nature of College English education). Waiyu Dianhua Jiaoxue (Computer-Assisted Foreign Language Education), 1, 9-14. https://doi.org/10.13458/j.cnki.flatt.004409

Cai, J., \& Liao, L. (2010). ELE haishi ESP, zailun woguo daxue yingyu de fazhan fangxiang (ELE vs. ESP--the orientation of college English). Waiyu Dianhua Jiaoxue (Computer-Assisted Foreign Language Education), 5, 20-26. https://doi.org/10.3969/j.issn.1001-5795.2010.05.004

Cunningsworth, A. (1995). Choosing your Coursebook. Oxford: Macmillan.

Gao, J. (2009). Gaoxiao zhuanmen yongyu yingyu jiaocai jianshe (College ESP textbook development). Waiyujie (Foreign Language World), 6, 84-90.

Ge, L. (2012). Gaoxiao ESP yingyu jiaocai de kaifa yu jianshe (Development of college ESP textbooks). Keji Yu Chuban (Science-Technology \& Publication), 6, 38-40. https://doi.org/10.16510/j.cnki.kjycb.2012.06.023

Guo, J. (2012). Zhuanmen Tongyu Yingyu Jiaoxue Yanjiu (Research on ESP Teaching). Beijing: Zhishi Chanquan Chubanshe (Intellectual Property Publishing House).

Hu, K., \& Xie, L. (2014). Woguo daxue yingyu jiaoxue de weilai fazhan fangxiang yanjiu (Study on future development of college English teaching in China). Waiyujie (Foreign Language World), 3, 12-19, 36.

Huang, P. (2007). Zhuanmen Yongtu Yingyu de Lilun yu Yingyong (The Theory and Application in English for Specific Purposes). Chongqing: Chongqing Daxue Chubanshe (Chongqing University Press).

Hutchinson, T., \& Waters, A. (1987). English for Specific Purposes: A learner-centred approach. Cambridge: Cambridge University Press.

Li, W. (2015). Gaoxiao zhuanmen yongtu yingyu pingjia tixi goujian yanjiu (Constructing a college ESP textbook evaluation system). Keji Yu Chuban(Science-Technology \& Publication), 10, 110-112. https://doi.org/10.16510/j.cnki.kjycb.2015.10.040

Liu, Y., \& Jia, Y. (2014). ESP jiaocai de jiben fenlei ji bianxie chuban wenti yu duice yanjiu(The category of ESP textbooks, problems of their publication and solutions). Chuban Faxing Yanjiu(Publishing Research), 9, 71-74. https://doi.org/10.19393/j.cnki.cn11-1537/g2.2014.09.023

Luo, N. (2014). Ligongke xueshuxing shuoshi yanjiusheng xushu yingyu xuqiu fenxi yanjiu:yi Wuhan Keji 
Daxue weili (EAP needs analysis of master of science and technology candidates following the academic track: A case study of Wuhan University of Science and Technology). Zhongguo ESP Yanjiu(Chinese Journal of ESP), 5(1), 24-32+88.

Mo, L. (2008). Zhuanmen Yongtu Yingyu Jiaoxue yu Yanjiu (A Study on English for Specific Purposes and Its Teaching). Hangzhou: Zhejiang Daxue Chubanshe (Zhejiang University Press).

Mo, Z. (2003). Zhuanye yingyu jiaocai jianshe: Wenti yu duice(ESP textbook development: Problems and Solutions). Waiyujie (Foreign Language World), (4), 66-71.

Song, M. (2017). MBA shangwu yingyu jiaocai pinggu biaozhun yanjiu (A research on evaluation criteria of MBA business English textbooks). Keji Yu Chuban(Science-Technology \& Publication), 7, 117-119. https://doi.org/10.16510/j.cnki.kjycb.2017.07.027

Sun, L. (2014). Cengci fenxifa zai ESP jiaocai shixiaoxing pingjia zhong de yingyong (Application of analytic hierarchy process to evaluation of ESP teaching materials effect). Tonghua Shifan Xueyuan Xuebao(Journal of Tonghua Normal University), 35(5), 113-115. https://doi.org/10.13877/j.cnki.cn22-1284.2014.10.039

Wang, H., \& Wang, Y. (2017). Jiyu yuliaoku de daxue yingyu zhuanye jiaocai pinggu fangfa de queli(The establishment of corpus-based evaluation approach of college ESP textbooks). Dangdai Jiaoyu Shijian Yu Jiaoxue Yanjiu(Contemporary Education Research and Teaching Practice), 12, 205. https://doi.org/10.16534/j.cnki.cn13-9000/g.2017.2556

Wang, S., \& Yao, C. (2013). Guanyu Xueshu yingyu jiaoxue de jidian sikao (Some thoughts on English for Academic Purposes(EAP) teaching). Zhongguo Waiyu (Foreign Languages in China), 10(5), 4-10. https://doi.org/10.13564/j.cnki.issn.1672-9382.2013.05.011

Wei, L. (2013). Gaoxiao zhuanmen yongyu yingyu jiaocai de wenti yu gaijin tantao(ESP textbooks and suggestions for improvement). Shijiazhuang Zhiye Jishu Xuayuan Xueyuan (Journal of Shijiazhuang Vocational Technology Institute), 25(3), 69-71. https://doi.org/10.3969/j.issn.1009-4873.2013.03.017

Wen, Q. (2014). Daxue yingyu jiaoxue zhong tongyong yingyu yu zhuanyong yingyu zhi zheng: Wenti yu duice (The conflict between EGP and ESP in College English teaching: Problems and solutions). Waiyu Yu Waiyu Jiaoxue (Foreign Languages and Their Teaching), 1, 10-8.

Yan, L. (2011). Zhuanmen Yongtu Yingyu Kecheng Jiangou (English for Specific Purposes: Curriculum Construction). Beijing: Zhongguo Chuanmei Daxue Chubanshe (Communication University of China Press).

\section{Copyrights}

Copyright for this article is retained by the author(s), with first publication rights granted to the journal.

This is an open-access article distributed under the terms and conditions of the Creative Commons Attribution license (http://creativecommons.org/licenses/by/4.0/). 